\title{
Long-term effects of oxygen-enriched high-flow nasal cannula treatment in COPD patients with chronic hypoxemic respiratory failure
}

This article was published in the following Dove Press journal: International Journal of COPD

\author{
Line Hust Storgaard' \\ Hans-Ulrich Hockey ${ }^{2}$ \\ Birgitte Schantz Laursen ${ }^{3,4}$ \\ Ulla Møller Weinreich ${ }^{1,3}$ \\ 'Department of Respiratory Diseases, \\ Aalborg University Hospital, \\ Aalborg, Denmark; ${ }^{2}$ Biometrics \\ Matters Limited, Hamilton, New \\ Zealand; ${ }^{3}$ Department of Clinical \\ Medicine, Aalborg University, Aalborg, \\ Denmark; ${ }^{4}$ Clinical Nursing Research \\ Unit, Aalborg University Hospital, \\ Aalborg, Denmark
}

Background: This study investigated the long-term effects of humidified high-flow nasal cannula (HFNC) in COPD patients with chronic hypoxemic respiratory failure treated with long-term oxygen therapy (LTOT).

Patients and methods: A total of 200 patients were randomized into usual care \pm HFNC. At inclusion, acute exacerbation of COPD (AECOPD) and hospital admissions 1 year before inclusion, modified Medical Research Council (mMRC) score, St George's Respiratory Questionnaire (SGRQ), forced expiratory volume in 1 second $\left(\mathrm{FEV}_{1}\right), 6$-minute walk test (6MWT) and arterial carbon dioxide $\left(\mathrm{PaCO}_{2}\right)$ were recorded. Patients completed phone interviews at 1,3 and 9 months assessing $\mathrm{mMRC}$ score and AECOPD since the last contact. At on-site visits (6 and 12 months), mMRC, number of AECOPD since last contact and SGRQ were registered and $\mathrm{FEV}_{1}, \mathrm{FEV}_{1} \%, \mathrm{PaCO}_{2}$ and, at 12 months, 6MWT were reassessed. Hospital admissions during the study period were obtained from hospital records. Hours of the use of HFNC were retrieved from the high-flow device.

Results: The average daily use of HFNC was 6 hours/day. The HFNC group had a lower AECOPD rate (3.12 versus 4.95/patient/year, $p<0.001$ ). Modeled hospital admission rates were 0.79 versus $1.39 /$ patient/year for 12 - versus 1 -month use of HFNC, respectively $(p<0.001)$. The HFNC group had improved mMRC scores from 3 months onward $(p<0.001)$ and improved SGRQ at 6 and 12 months $(p=0.002, p=0.033)$ and $\mathrm{PaCO}_{2}(p=0.005)$ and $6 \mathrm{MWT}(p=0.005)$ at 12 months. There was no difference in all-cause mortality.

Conclusion: HFNC treatment reduced AECOPD, hospital admissions and symptoms in COPD patients with hypoxic failure.

Keywords: COPD, high-flow heated and humidified oxygen, HFNC, exacerbation, AECOPD, modified Medical Research Council score, mMRC score, 6-minute walk test, 6MWT

\section{Introduction}

In advanced COPD, long-term oxygen therapy (LTOT) is an established treatment for patients with chronic hypoxemic respiratory failure. LTOT has been shown to increase the survival in patients with severe resting hypoxemia, with optimal use of $\geq 15$ hours/day. ${ }^{1,2}$ The prevalence of LTOT in COPD is 40-48/100,000 patients and is increasing. ${ }^{3,4}$ Adherence to optimal treatment has proved difficult. ${ }^{5}$ Despite improved survival when treated with LTOT, life expectancy is limited when in need of LTOT, in part due to concomitant comorbidities and hypercapnic failure, ${ }^{3,6,7}$ although it has been indicated that LTOT stabilizes the partial pressure of arterial carbon dioxide $\left(\mathrm{PaCO}_{2}\right){ }^{8}$ Moreover, patients are susceptible to acute exacerbation of COPD (AECOPD),${ }^{9}$ with poor outcomes in terms of mortality and recurrence of AECOPD. ${ }^{10}$
Correspondence: Ulla Møller Weinreich Department of Respiratory Diseases, Aalborg University Hospital, Mølleparkvej 4, DK-9000 Aalborg, Denmark

Tel +459766 4735

Email ulw@rn.dk
International Journal of COPD 20|8:13 ||95-1205

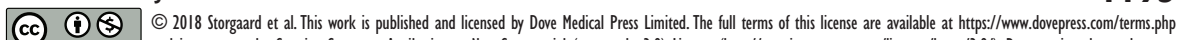
cc. hereby accept the Terms. Non-commercial uses of the work are permitted without any further permission from Dove Medical Press Limited, provided the work is properly attributed. For permision for commercial use of this work, please see paragraphs 4.2 and 5 of our Terms (https://www.doveperess. com/terms.php). 
In addition, patients are highly symptomatic, ${ }^{11}$ have impaired quality of life (QoL) $)^{12}$ and limited walking distances, none of which improve with LTOT. ${ }^{13}$

Humidified high-flow nasal cannula (HFNC) with optional supplementary oxygen delivery has evolved in recent years, with a growing body of evidence of reduced respiratory resistance, decreased work load of breathing, improved pulmonary compliance, recruitment and mucus clearance in adults. ${ }^{14-16}$ HFNC is primarily established in acute and critical care settings for treating mild-to-moderate acute hypoxic failure ${ }^{17}$ and ventilator weaning. ${ }^{18}$ However, there is increasing evidence that HFNC is beneficial in chronic respiratory diseases. Recent studies have shown increased time to first exacerbation and forced expiratory volume in 1 second $\left(\mathrm{FEV}_{1}\right)$ in patients with obstructive lung diseases and mucus retention challenges, ${ }^{19}$ in addition to a reduction in respiratory rate, ${ }^{20} \mathrm{PaCO}_{2}{ }^{21}$ and increased exercise performance $^{22}$ in advanced COPD patients and patients with chronic hypoxemic respiratory failure. However, knowledge about the long-term effect of HFNC is sparse.

Thus, we hypothesize that in COPD patients with chronic hypoxemic respiratory failure, long-term HFNC may reduce AECOPD rate, dyspnea and mortality as well as increase exercise performance. The aim of this study was to investigate the effects of long-term HFNC in conjunction with usual care, including LTOT, with the primary outcome being the rate of AECOPD, and, as secondary outcomes, hospital admissions; dyspnea, assessed by modified Medical Research Council (mMRC) score; QoL, assessed by St George's Respiratory Questionnaire (SGRQ); $\mathrm{PaCO}_{2}$; all-cause mortality and exercise performance, measured by 6-minute walk test (6MWT).

\section{Patients and methods}

In this randomized, prospective trial a total of 200 patients were included from 4 outpatient clinics in the North Jutland Region of Denmark between December 2013 and July 2015 (Figure 1). Inclusion criteria were COPD with chronic hypoxemic respiratory failure (ie, 3 arterial blood gases [ABGs] during stable conditions demonstrating hypoxemia) ${ }^{23}$ and previously prescribed LTOT by a pulmonary medicine specialist, at least 3 months prior to the start of the study. Exclusion criteria were malignant disease, terminal nonmalignant disease, unstable psychiatric disease and home treatment with noninvasive ventilation (NIV). A change in smoking habits during the study period would lead to exclusion. All patients received personalized inhaled medicine according to Global Initiative for Chronic Obstructive Lung Disease (GOLD) guidelines, ${ }^{24}$ had previously undergone pulmonary rehabilitation and were in specialized care in connection with LTOT treatment, according to the GOLD recommendations. ${ }^{25}$ Change of medication and attending rehabilitation were allowed, if recommended by the patients' usual caregivers.

\section{Inclusion}

By the use of numbered sealed envelopes containing group allocations, patients were randomly assigned to either LTOT (controls) or LTOT plus HFNC home treatment delivered by Airvo $^{\text {TM }}$ via Optiflow ${ }^{\mathrm{TM}}$ nasal cannula (both; Fisher \& Paykel Healthcare, Auckland, New Zealand). A recommended $20 \mathrm{~L} / \mathrm{min}$ flow rate was decided upon after an unpublished pilot test determined that this was comfortable and allowed high compliance during sleep. Starting at $15 \mathrm{~L}$, flow was titrated over 30 minutes at the baseline visit. Patients were instructed in use of the device, received a written quick guide to the device and were recommended to use HFNC for 8 hours/day, preferably at night; however, there were no restrictions in the duration of use nor time of day.

At inclusion, age, sex, body mass index (BMI), smoking status including pack-years, number of AECOPD events during the previous year, months treated with LTOT prior to inclusion and administered LTOT (L/min) flow was recorded. Dyspnea was evaluated by $\mathrm{mMRC}$ score, and QoL was assessed using SGRQ.

Spirometry was performed (Spida spirometry PC software/MicroMedical SpiroUSB ${ }^{\text {TM}}$; CareFusion, San Diego, CA, USA) according to the American Thoracic and European Respiratory Societies' criteria. ${ }^{26} \mathrm{FEV}_{1}$, forced vital capacity (FVC) in the percentage of expected value and the $\mathrm{FEV}_{1} / \mathrm{FVC}$ ratio were recorded.

ABG analysis was performed in all patients during the administration of usual supplementary oxygen ${ }^{27}$ (ABL 800 Flex blood gas analyzer; Radiometer, Copenhagen, Denmark). $\mathrm{pH}, \mathrm{PaCO}_{2}$, partial pressure of oxygen $\left(\mathrm{PaO}_{2}\right)$ and arterial oxygen saturation $\left(\mathrm{SaO}_{2}\right)$ were recorded. The supplementary oxygen flow rate was kept unaltered during HFNC treatment unless $\mathrm{SaO}_{2}<88 \%$ was detected. Hypercapnic failure was defined as $\mathrm{PaCO}_{2}>6.0 \mathrm{kPa}$.

A 6MWT was performed, ${ }^{28}$ with patients using usual oxygen flows and use of walkers if needed. Initial oxygenpulsed saturation $\left(\mathrm{SpO}_{2}\right)$, heart rate $(\mathrm{HR}$, beats/min) as well as minimum $\mathrm{SpO}_{2}$ and maximal $\mathrm{HR}$, walking distance and BORG score at the end of 6MWT were recorded.

Both the HFNC and control groups received medical care by their usual health care providers during the study period, including treatment for AECOPD. Patients were instructed to keep diary cards for registration of number of AECOPD events treated outside hospital. 


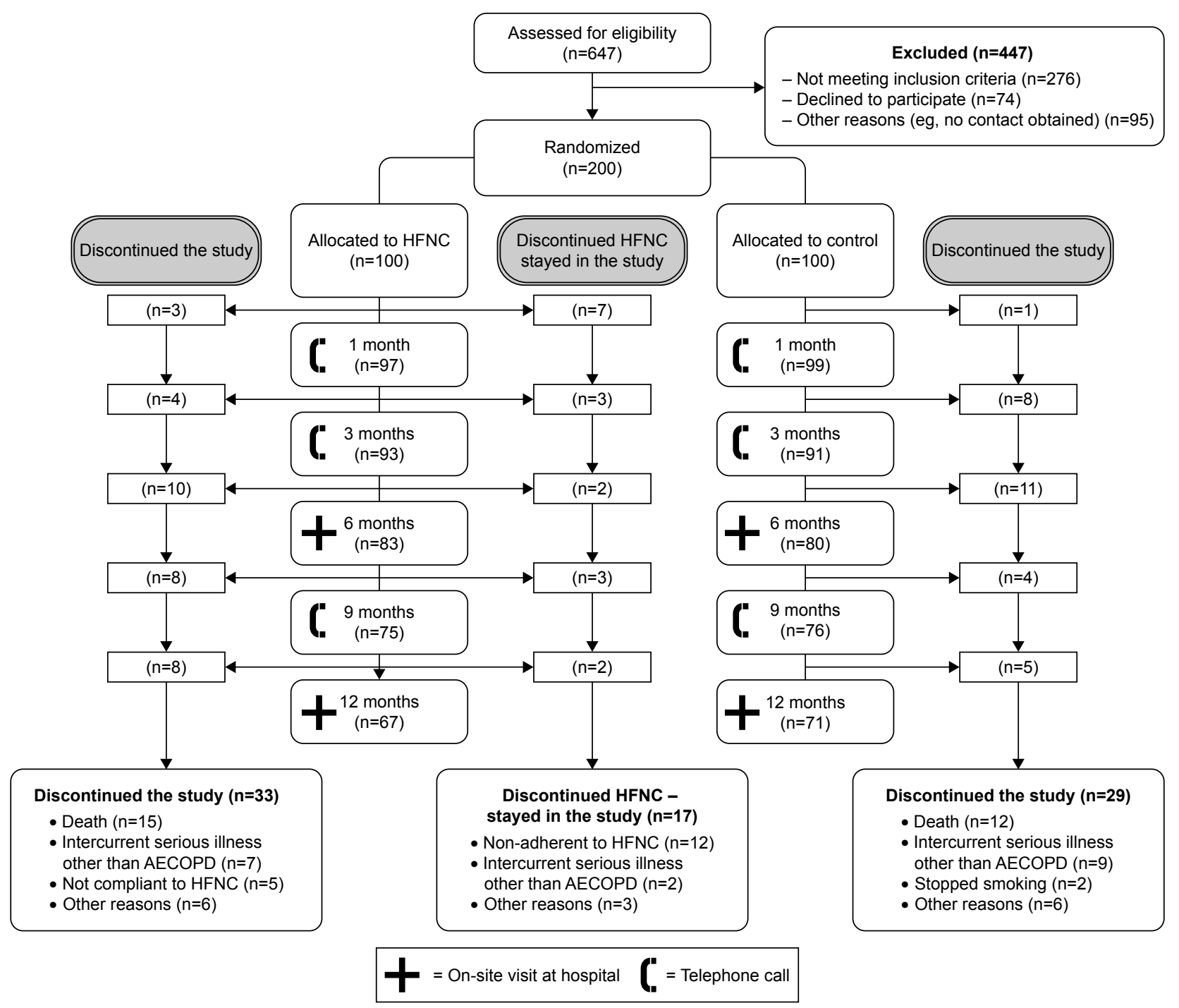

Figure I Enrollment, inclusion, follow-up and discontinuation of HFNC-treated patients and controls. Abbreviations: AECOPD, acute exacerbation of COPD; HFNC, high-flow nasal cannula.

The usual providers of LTOT homecare for both the treatment and control groups, AGA, Linde Healthcare, Dronninglund, Denmark, delivered and serviced the HFNC system during regular home visits. Re-instruction in use of the device was given by the technical staff at home delivery of HFNC. All patients used the HFNC device with oxygenenriched air.

\section{Follow-up}

Follow-up is shown in Figure 1. During the 1-year trial period, 2 Aalborg University Hospital study nurses conducted phone interviews at 1, 3 and 9 months and in-clinic visits at 6 and 12 months for both HFNC-treated patients and controls. Study nurses did not perform home visits.

AECOPD was defined as worsening of symptoms (worsening of dyspnea, cough and sputum production) for $>2$ consecutive days leading to treatment with systemic glucocorticoids or antibiotics. ${ }^{25}$ Diary cards for AECOPD were read at each contact. If in doubt, patients were instructed to consult the study nurse in addition to scheduled phone interviews, where all registered AECOPDs on diary cards were recorded in the study file. In conjunction, the number of hospital admissions (at least 24-hour inpatient contact) due to AECOPD (primary diagnosis of COPD [ICD-10: DJ44], or a combination of either acute respiratory failure [DJ96] or pneumonia [DJ13-18] with COPD as a secondary diagnosis) was evaluated at the end of the study period from patients' hospital case records.

mMRC score and smoking status were evaluated at each contact.

Lung function and BMI were measured, and SGRQ was evaluated at 6- and 12-month visits.

ABGs were drawn while patients were on usual LTOT at 6- and 12-month visits. After 30 minutes of HFNC treatment 
in patients who were allocated to treatment, $\mathrm{ABG}$ analysis was repeated. The need to change oxygen levels during the use of HFNC was evaluated at each visit.

The 6MWT was repeated at 12 months with recording of BORG score and HR.

In the HFNC group, patients reported their daily hours of HFNC therapy and diurnal pattern of use at each contact. In conjunction, the technical staff read operating hours from the HFNC device every second month and the average use (hours/day since the last reading) was calculated.

\section{Ethics}

The study was approved by the North Jutland Ethical Committee (N-20110057), the Danish Data Protection Agency (2008-58-0028), and registered at ClinicalTrials.gov (NCT 02731872). All patients were informed according to the Declaration of Helsinki, and written informed consent was obtained prior to inclusion in the study.

\section{Statistical analysis}

Sample sizing was based on AECOPD rate being reduced by $20 \%$ from an historical estimate of 3.80/patient/year. Group size of 93 gives $80 \%$ power with a 2 -sided $5 \%$ level of significance, which was increased to 100 to be conservative. Patients were encouraged to remain in the study for assessments even if HFNC was no longer used (Figure 1).

The analysis population was defined as all subjects randomized to treatment and who had no major protocol deviations affecting efficacy data, giving 100\% inclusion of all 200 subjects enrolled. As such, data were included on patients who discontinued the study or paused treatment and those who discontinued HFNC but stayed in the study, in the HFNC group (intention-to-treat).

Background and pretreatment information is provided as mean and SD.

Normally distributed data were analyzed in the general linear model framework with the simplest model of treatment group augmented by covariates of age and sex and, where available, baseline value of the dependent variable. Poisson regression modeling of both AECOPD and hospital admissions per patient was completed with the length of time in the study used to give estimated rates per year per treatment group with the same explanatory model as mentioned earlier. Analyses using the 2 groups as randomized are akin to intention to treat. The extra analyses where the 2 groups of treatment were replaced by 1 continuous explanatory variable of actual days of the use of HFNC are akin to per protocol. Fitted values from modeling were used to assess the treatment effect adjusted for other model terms.

\section{Results \\ Background}

Baseline information of the study population is reported in Table 1.

HFNC-treated patients and controls were comparable at baseline, apart from mMRC score, where HFNC-treated patients had a higher mMRC score. Concomitant hypercapnic failure was seen in $60 \%$ of controls and $52 \%$ of HFNC-treated patients. Average days in the study were 309 days for HFNCtreated patients, comparable to controls at 311 days. Mean oxygen flow during LTOT remained unaltered at 12 months in both groups $(1.6 \mathrm{~L} / \mathrm{min}$ in the HFNC group and $1.7 \mathrm{~L} / \mathrm{min}$ in the control group).

\section{HFNC}

Overall, on average, HFNC was used for 248 days, 6 hours/day, throughout the study period (readings from the HFNC device). Within the first month, 14\% of HFNC-treated patients stopped using the device, including 3\% who left the study entirely. The remaining $86 \%$ used HFNC for 286 days, 7 hours/day on average, throughout the study period. HFNC was used at night by $53 \%$ of the patients; during the day by $32 \%$ and both at night and day by $15 \%$. Patients using HFNC at night, or both night and day, used the device significantly longer than those using only during daytime $(p<0.003)$. By the end of study, 33\% of the HFNC group had left the study, compared to $29 \%$ of the control group (Figure 1). Reasons for leaving the study or discontinuing HFNC are shown in Figure 1.

No adverse or serious adverse events were recorded.

\section{Exacerbations and hospital admissions}

AECOPD rates were significantly lower in the HFNC group than the control group, 3.12 versus 4.95/patient/year, $p<0.001$ (Figure 2A).

A reduction in AECOPD is also seen with increasing use of HFNC $(p<0.001)$, using the actual number of days of the use of HFNC as an explanatory continuous variate (eg, zero for the control group; Figure 2B). This predicts an AECOPD rate of 4.78/patient/year for zero use and 2.89/patient/year for 1 year of use for the average patient with 3 AECOPDs in the previous year.

There was no significant group difference in hospital admission rates (placebo: 1.22/patient/year, HFNC: 1.08/ patient/year, $p=0.373$; Figure 2C). However, using the actual number of days of the use of HFNC as an explanatory 
Table I Background information on the randomized study population, humidified HFNC-treated patients and controls at baseline

\begin{tabular}{|c|c|c|c|}
\hline Variables at baseline & $\begin{array}{l}\text { HFNC-treated } \\
\text { patients }(n=100)\end{array}$ & $\begin{array}{l}\text { Controls } \\
(n=100)\end{array}$ & $\begin{array}{l}p \text {-value for } \\
\text { group difference }\end{array}$ \\
\hline Sex, \% female & 56 & 63 & NS \\
\hline Age, years & $71.0(8.2)$ & $70.4(9.0)$ & NS \\
\hline Treated with LTOT prior to inclusion, months & $28.9(32.6)$ & $33.5(30.6)$ & NS \\
\hline $\mathrm{BMI}, \mathrm{kg} / \mathrm{m}^{2}$ & $25.0(6.4)$ & $25.4(6.0)$ & NS \\
\hline Smoking status, N, never/present/former & $\mathrm{I} / \mathrm{I} / 85$ & $0 / 26 / 74$ & NS \\
\hline Pack-years & $4 I .7(17.8)$ & $40.5(19.5)$ & NS \\
\hline mMRC score & $3.3(0.9)$ & $2.9(0.9)$ & 0.008 \\
\hline Exacerbations in the preceding year & $3.23(3.1)$ & $2.9(2.8)$ & NS \\
\hline Current oxygen flow, L & $1.6(0.7)$ & $1.6(0.8)$ & NS \\
\hline $\mathrm{pH}$ & $7.41(0.04)$ & $7.4 I(0.02)$ & NS \\
\hline $\mathrm{PaCO}_{2}, \mathrm{kPa}$ & $6.5(1.3)$ & $6.4(1.0)$ & NS \\
\hline $\mathrm{PaO}_{2}, \mathrm{kPa} *$ & $9.9(1.8)$ & $9.9(1.7)$ & NS \\
\hline $\mathrm{SaO}_{2}$ & $95(3.1)$ & $95(2.7)$ & NS \\
\hline $\mathrm{FEV}_{1} \%$ & $29.8(12.6)$ & $31.8(12.9)$ & NS \\
\hline FVC\% & $64.1(18.2)$ & $63.9(19.0)$ & NS \\
\hline $\mathrm{FEV}_{1} / \mathrm{FVC}$ & $37.5(11.1)$ & $40.2(10.3)$ & NS \\
\hline 6MWT (N), m & (91) $254.6(89.2)$ & (96) $245.2(85.0)$ & NS \\
\hline Borg score, end of test & $6.3(2.3)$ & $6.2(2.3)$ & NS \\
\hline HFNC flow, L & $20(I .1)$ & & \\
\hline Oxygen supply with HFNC, L & $\mathrm{I} .75(0.8)$ & & \\
\hline $\mathrm{pH}$ after 30 minutes of HFNC & $7.42(0.03)$ & & \\
\hline $\mathrm{PaCO}_{2}$ after 30 minutes of $\mathrm{HFNC}, \mathrm{kPa}$ & $6.2(1.2)$ & & \\
\hline $\mathrm{PaO}_{2}$ after 30 minutes of $\mathrm{HFNC}, \mathrm{kPa}$ & $8.9(1.2)$ & & \\
\hline $\mathrm{SaO}_{2}$ after 30 minutes of $\mathrm{HFNC}, \mathrm{kPa}$ & $94(2.6)$ & & \\
\hline
\end{tabular}

Notes: Results are presented as mean (SD) unless otherwise stated. *ABG on usual supplementary oxygen supply.

Abbreviations: ABG, arterial blood gas; BMI, body mass index; $\mathrm{FEV}_{1}$, forced expiratory volume in I second; FVC, forced vital capacity; HFNC, high-flow nasal cannula; LTOT, long-term oxygen therapy; mMRC, modified Medical Research Council; 6MWT, 6-minute walk test; NS, nonsignificant; Pa, arterial partial pressure; Sa, arterial saturation.

continuous variate (eg, zero for the control group; Figure 2D), a reduction in hospital admissions was seen (using previous year admissions as baseline covariate), which predicts an admission rate of $1.39 /$ year for zero use and $0.79 /$ year for 1 year of use for the average patient with 1 admission in the previous year $(p>0.001)$.

Figure 3 shows, in a fitted model, how the study year exacerbation rates relate to the previous year's exacerbations, $p<0.001$, by the treatment group.

\section{mMRC score}

Fitted change in mMRC score for HFNC-treated patients and controls over the 12-month period is shown in Figure 4A. At 3 months, HFNC-treated patients had improved mMRC scores $(p<0.05)$, and from 3 months onward they had lower mMRC scores compared to controls $(p<0.001)$.

\section{QoL}

Changes in SGRQ total score are shown in Figure 4B. HFNCtreated patients were stable, while controls had a clinically significant deterioration of 4.38 over 12 months. As such, HFNC-treated patients had better SGRQ at both $6(p=0.002)$ and 12 months $(p=0.033)$ compared to controls.

\section{$\mathrm{PaCO}_{2}$}

Fitted means for $\mathrm{PaCO}_{2}$ are plotted in Figure 4C. Over 12 months, $\mathrm{PaCO}_{2}$ for HFNC-treated patients decreased while it increased for controls, resulting in a significant difference between groups at 12 months $(p=0.005)$. At baseline, a $0.29 \mathrm{kPa}$ reduction in $\mathrm{PaCO}_{2}$ was seen after 30 minutes of HFNC treatment. Similar reductions were seen at $6(0.28 \mathrm{kPa})$ and 12 months $(0.26 \mathrm{kPa})$.

\section{MWT}

Fitted means for 6MWT are shown in Figure 4D with a significant difference at 12 months, $p=0.005$, excluding non-walkers. No differences were seen in Borg score or HR.

\section{Lung function, oxygen levels and BMI}

A tendency toward increased $\mathrm{FEV}_{1} \%$ in HFNC-treated patients at 6 and 12 months was seen relative to controls ( $p=0.084$ and $p=0.056$, respectively).

A minority of HFNC-treated patients required LTOT oxygen flow rates to be increased. At baseline, this was 15 patients $(1.0 \pm 0.5 \mathrm{~L} / \mathrm{min})$, at 6 months 11 patients $(1.2 \pm 1.0 \mathrm{~L} / \mathrm{min})$ and 
A

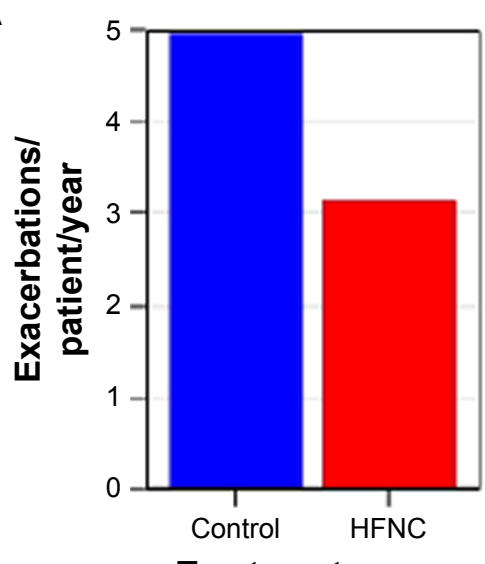

Treatment group

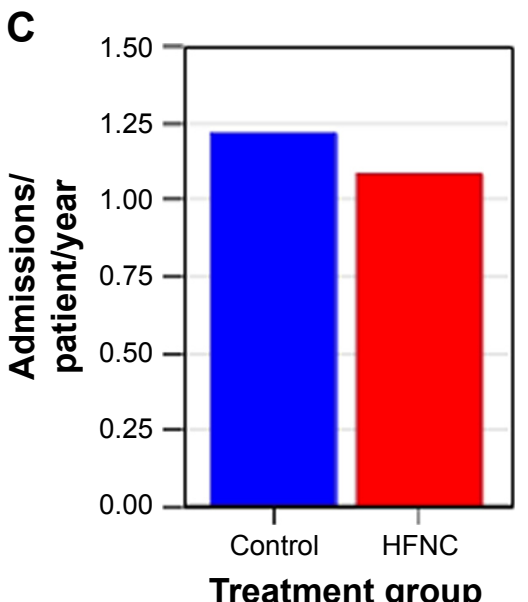

C

Treatment group
B

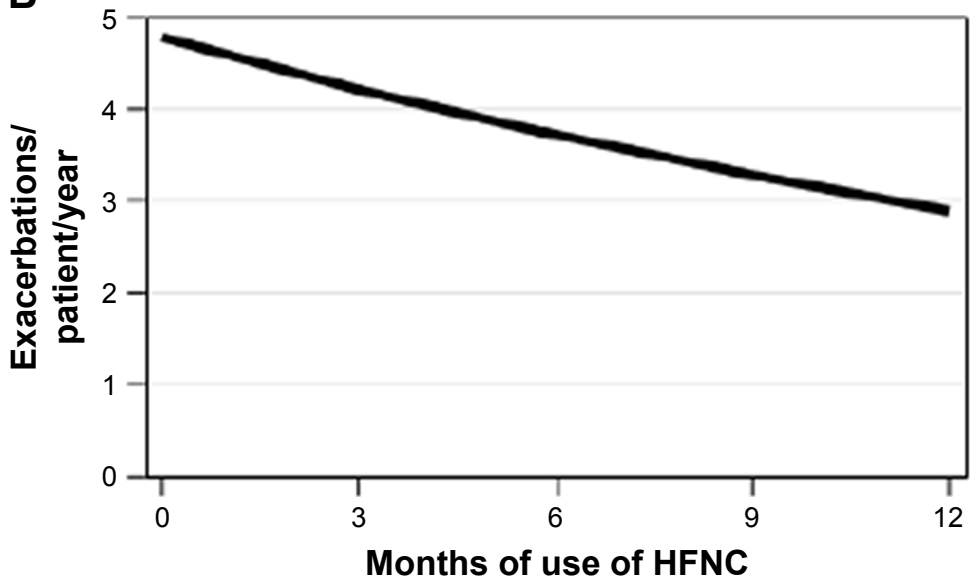

D

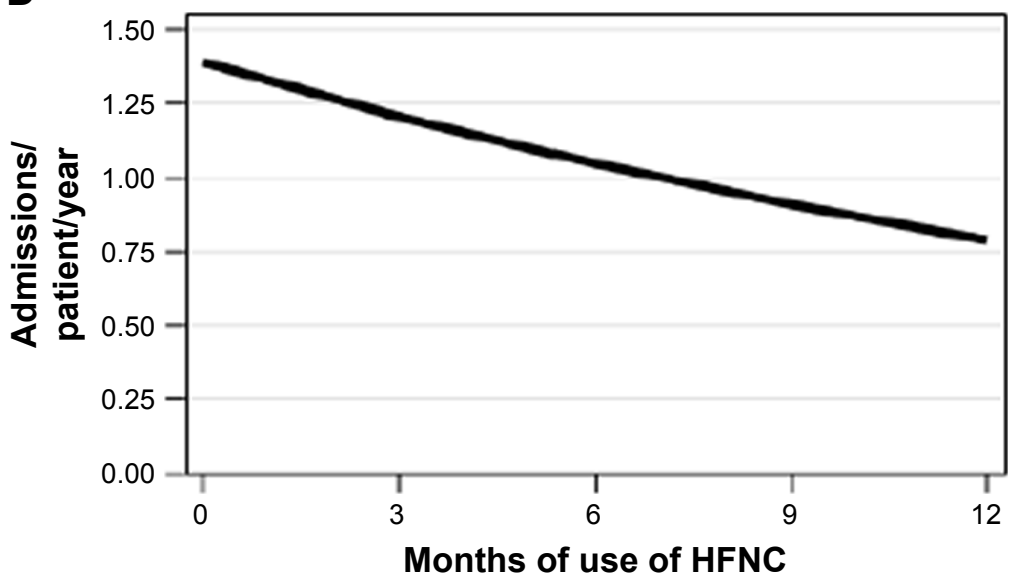

Figure 2 Fitted exacerbation rates (combined reported exacerbations and hospitalized exacerbations) (A, B) and hospital admission rates (C, D).

Notes: In (A and $\mathbf{C}$ ), blue (control) and red (HFNC) bars show rates per group as randomized (intention-to-treat analysis). In (B and $\mathbf{D}$ ), the regression line for exacerbations (B) and admissions (D) relates actual device use, zero for the control group and 12 months for the study completers, with withdrawal subjects ranging in between (perprotocol analysis) to the number of events per patient, showing longer actual use giving lower rates of exacerbation and admission.

Abbreviation: HFNC, high-flow nasal cannula.

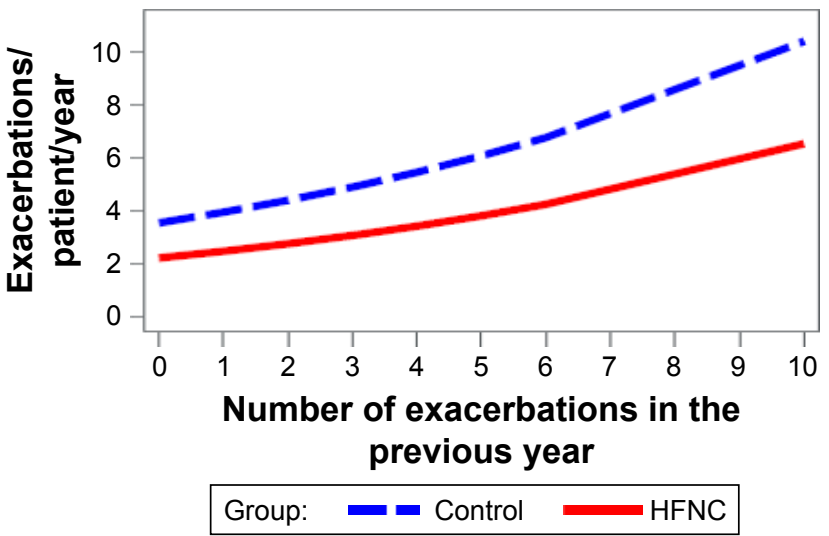

Figure 3 Fitted values, based on number of exacerbations in the year prior to study, of the expected number of exacerbations with zero use (blue dashed) and the HFNC-treated (red solid).

Abbreviation: HFNC, high-flow nasal cannula. at 12 months 9 patients $(1.2 \pm 1.1 \mathrm{~L} / \mathrm{min})$. The decrease in the number of patients requiring increased oxygen flow on HFNC was mainly due to dropout.

There were no significant differences in baseline-adjusted changes in $\mathrm{FVC} \%, \mathrm{FEV}_{1} / \mathrm{FVC}, \mathrm{pH}, \mathrm{PaO}_{2}$ or $\mathrm{SaO}_{2}$ between the groups at 6 or 12 months. A significant increase in BMI in HFNC-treated patients compared to controls was seen at 6 months ( 25.7 versus 25.3 , respectively, $p=0.04$ ). However, this was no longer present at 12 months.

\section{Mortality}

There was no difference in all-cause mortality between treatment groups; $15 \%$ for HFNC-treated patients and $12 \%$ for controls ( $p=0.636$; Figure 1). In the HFNC group, 4 out 

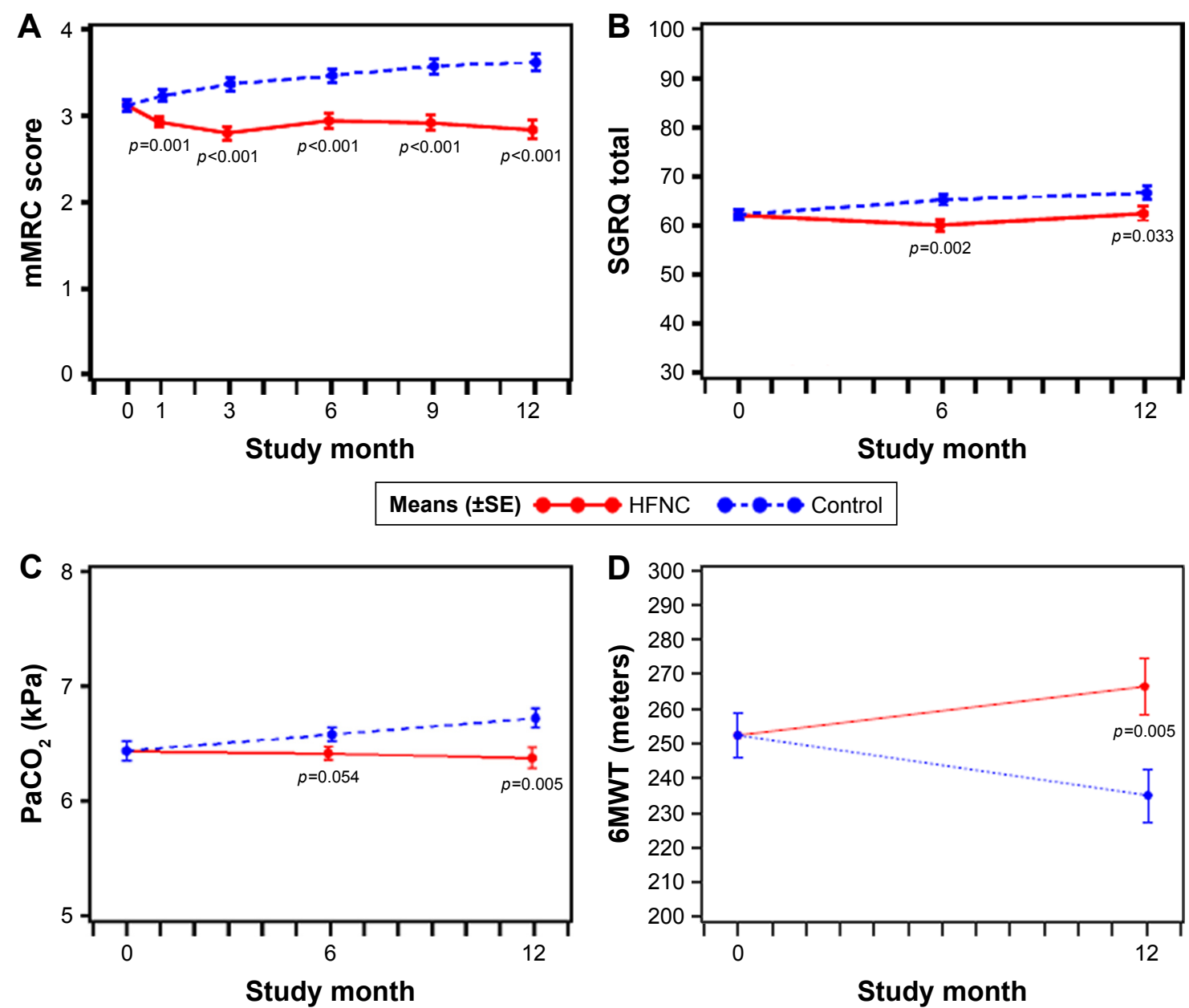

Figure 4 Fitted data on mMRC score (A), SGRQ (B), arterial partial pressure of $\mathrm{CO}_{2}(\mathbf{C})$ and $6 \mathrm{MWT}$ (D), in high-flow, humidified, nasal cannula delivered oxygen (HFNC) patients (red solid line) or controls (blue dashed lines) during the study.

Notes: Dots represent assessment times. p-values show differences between the HFNC and control groups.

Abbreviations: HFNC, high-flow nasal cannula; mMRC, modified Medical Research Council; 6MWT, 6-minute walk test; SE, standard error; SGRQ, St George's Respiratory Questionnaire.

of 15 patients discontinued treatment prior to and not in connection to death. No association was found between allcause mortality and exacerbations.

\section{Discussion}

This is the first study reporting on 12 months of treatment of LTOT-treated COPD patients using HFNC in a home setting.

In this study, for COPD patients who were prescribed LTOT, consistent use of HFNC significantly reduced AECOPD and hospitalization. Furthermore, HFNC significantly reduced mMRC score and preserved SGRQ and 6MWD, while the control group measures deteriorated. A reduction in $\mathrm{PaCO}_{2}$ was seen in HFNC-treated patients with significant differences in $\mathrm{PaCO}_{2}$ levels at 12 months compared to controls. Finally, no significant difference was seen in all-cause mortality between the 2 groups.
The significant reduction in AECOPD in HFNC-treated patients compared to controls is in agreement with a previous study by Rea et al, ${ }^{19}$ where HFNC significantly increased time to first exacerbation. However, Rea et al's study differs in 2 important ways from this study. First, the study population; Rea et al's study included a mixed population of patients with obstructive lung diseases with better lung function and few with hypoxic failure compared to those included in this study. AECOPD is known to be the strongest predictor for future exacerbations, ${ }^{29,30}$ and patients with chronic hypoxemic respiratory failure are known to be even more susceptible to AECOPD than normoxic patients, ${ }^{29,31}$ consistent with the control group in this study where the number of AECOPD events increases over time. However, HFNC significantly reduced the risk of $A E C O P D$, with the risk reducing with increasing with HFNC treatment time. In our opinion, this strongly supports the preventive effect of HFNC treatment on exacerbations, 
even in very severe COPD patients. HFNC may therefore prove to be a novel and an effective non-pharmacological treatment adjunct for this group of very severely ill patients.

Second, in Rea et al's study, HFNC was only used 1-2 hours/day, compared to the current study with an average use of 6-7 hours/day. While Rea et al's study did not find a significant reduction in exacerbations, this study did. This indicates that the duration of the use of HFNC is important for the reduction in AECOPD. However, this needs further scientific substantiation.

In this study, mMRC score improved significantly throughout the study period in HFNC-treated patients in contrast to controls, where a deterioration was observed. Even when following recommended medical treatment, dyspnea is one of the most common symptoms of severe COPD with a large impact on patient lives. ${ }^{32,33}$ The most effective treatment of dyspnea is rehabilitation, ${ }^{34}$ yet adherence is difficult in more severely ill patients. ${ }^{35}$ In a recent Cochrane review, the effect of oxygen treatment on dyspnea proved to be modest. ${ }^{36}$ The observed effect of HFNC on symptoms is therefore notable and substantiates the role of HFNC treatment in COPD chronic care.

This study provides a rare and thorough description of the development in clinical features and patho-physiological findings in advanced COPD patients with hypoxic failure. Despite the control group receiving the recommended treatment for this patient group, they still experienced increased hypercapnia, decreased lung function, walking distance and QoL. This is consistent with previous findings and is associated with poor prognosis. ${ }^{37}$ This study demonstrates that the long-term HFNC treatment decelerates disease progression, as seen with 6MWD, QoL and $\mathrm{PaCO}_{2}$. The significant difference in $\mathrm{PaCO}_{2}$ between the HFNC-treated and controls after 12 months is consistent with a recent study by Nagata et al, ${ }^{38}$ despite only half the patients being hypercapnic at inclusion. In comparison, in a recent metaanalysis on nocturnal NIV, an alternative add-on treatment for severe COPD patients with hypercapnic failure, there were no significant differences between the treatment and control groups in 6MWD, QoL or $\mathrm{PaCO}_{2}$ after 12 months of treatment. ${ }^{39}$ This suggests that HFNC may be superior to NIV in slowing disease progression, although further investigation is required to substantiate this. The physiologic mechanism behind these improvements is as follows: as a flow of $20 \mathrm{~L} / \mathrm{min}$ provides a positive expiratory pressure (PEP) of less than $2 \mathrm{~cm} \mathrm{H}_{2} \mathrm{O},{ }^{17}$ the PEP effect is possibly of lesser importance. Despite providing open circuit ventilation, HFNC has been shown to increase inspiratory tidal volume in COPD, especially when used during daytime use, ${ }^{40,41}$ whereas nighttime use has been shown to relieve respiratory load. ${ }^{41}$ Clearance of anatomical dead space is probably important for the reduction in $\mathrm{PaCO}_{2}{ }^{42}$ However, the most important effect in COPD chronic care is most likely improved mucociliary clearance, driven by the humidification of the air delivered by high flow to distal airways. ${ }^{17}$ This may enhance recruitment, improve alveolar ventilation and reduce patients' respiratory workload. All these mechanisms together would decrease the patients' sensation of dyspnea and thereby increase physical ability and, as previously indicated, reduce exacerbations. ${ }^{19,43}$ As such, this study suggests that HFNC should be a treatment used in conjunction with LTOT in COPD patients with hypoxic failure to reduce exacerbations and maintain health status in general.

The daily duration of the use of HFNC increased when patients included nighttime use. Recommended flow was based only on the experience of patients' tolerability; therefore, further investigation is needed. However, based on this study, we recommend that the use should preferably be during sleep, with a flow of at least $20 \mathrm{~L} / \mathrm{min}$.

This study has some limitations. A randomized blinded study could have been wished for, however, blinding the patients against the flow, the heat and the humidity is not realistic. Data on active hours of use of LTOT may have been interesting; however, oxygen delivery device actual use is not currently available, and patients' self-report usage is inaccurate.

Recall bias is possible for AECOPD, and patients' activities, such as rehabilitation, could influence results if not evenly distributed within the 2 groups. Differences in prescribed medicine and participation in rehabilitation could also potentially influence results. However, as patients were randomly allocated to the HFNC and control groups, were all treated according to guidelines, including referral to vaccination and rehabilitation according to national guidelines ${ }^{44}$ and received the same standard of care and visits from the LTOT homecare company, we expect this to be similar between the 2 groups.

The recommendation of 8 hours of the use of HFNC has no real scientific background. The only previous long-term study recommended 2 hours of use per day, resulting in 1.6 hours of use on average. Studies on LTOT compliance have showed that mobility is important to obtain compliance, and this study shows that daytime users use HNFC significantly less than nighttime users. An average use of HFNC in patients including nighttime use close to the recommended 8 hours does tell us that this is applicable. However, further studies are needed to decide the duration of optimal use. Furthermore, this study allowed both day- and nighttime use of HFNC. The physiological mechanisms of HFNC 
have previously been suggested to be different at day- and nighttime, however, this study was performed in healthy individuals and the population therefore not necessarily comparable to our study population. ${ }^{41}$ A comparison of the effect of day- and nighttime use would be ideal, but was not performed in this study as differences in duration of use also occur between day- and nighttime use.

One-seventh of the HFNC group ceased treatment within the first month, although only 3\% left the study population completely, while $44 \%$ of the study population discontinued the use of HFNC during the observation period. However, more than one-quarter of those who discontinued died during the study. This is substantial, but consistent with prospective studies of NIV on comparable patient populations with similar treatment durations in the home. ${ }^{45,46}$ There is of course a risk that those who were non-adherent were patients who did not feel any physical amelioration, or even felt worse, using HFNC. However, as results from the treatment group also included those who discontinued use of HFNC but stayed in study and as overall study time was similar between the treatment groups and controls this is not a likely explanation. Retention rates on this study were similar, but by definition, patients remained in the control arm longer than in the HFNC arm. Therefore, group comparisons were as randomized and more in line with an intent-to-treat paradigm. The analyses of exacerbations and admissions using actual days of the use of $\operatorname{HFNC}$ (eg, zero for the control group) were closer to a per-protocol paradigm.

The choice of included variables is always contentious. As such, the use of other established symptom scores, eg, the COPD assessment test, could have substantiated and elaborated description of patients' symptoms. In addition, the clinical relevance of some of the changes, ie, $\mathrm{PaCO}_{2}$, is arguable. The changes did not lead to significant changes of $\mathrm{pH}$; perhaps patients were able to compensate. However, $\mathrm{PaCO}_{2}$ levels have previously been shown to affect the outcome of AECOPD in patients with chronic hypoxemic respiratory failure, ${ }^{47}$ even when the $\mathrm{PaCO}_{2}$ values were lower than those demonstrated in this study. Therefore, the reduction in $\mathrm{PaCO}_{2}$ could have clinical benefit.

\section{Conclusion}

This study shows that in COPD with hypoxic failure treated with LTOT, adjunct HFNC therapy reduces exacerbations, admissions and symptoms. In addition, HFNC stabilizes the clinical condition of advanced COPD patients, but does not improve all-cause mortality. In future, HFNC should therefore be considered a beneficial adjunct to the recommended treatment of COPD patients with chronic hypoxemic respiratory failure.

\section{Acknowledgments}

We thank Jens Kure, Sales Manager at Home Care, Linde Healthcare, Denmark, and employees for technical support and supportive care of our study population. Fisher \& Paykel Healthcare delivered the AIRVO HFNC devices and contributed to the funding of this study, as did the North Jutland Region, Denmark. Data are exclusively authors' property.

\section{Author contributions}

Line Hust Storgaard participated in conception and design, data collection and drafting the manuscript for important intellectual content. Hans-Ulrich Hockey participated in conception and design, analysis and interpretation and drafting the manuscript for important intellectual content. Birgitte Schantz Laursen participated in conception and design and drafting the manuscript for important intellectual content. Ulla Møller Weinreich participated in conception and design, data collection, analysis and interpretation and drafting the manuscript for important intellectual content. All authors contributed toward data analysis, drafting and revising the paper and agree to be accountable for all aspects of the work.

\section{Disclosure}

Hans-Ulrich Hockey received remuneration from Fisher \& Paykel, who also contributed equipment and some administration costs. The authors report no other conflicts of interest in this work.

\section{References}

1. Report of the Medical Research Council Working Party. Long term domiciliary oxygen therapy in chronic hypoxic cor pulmonale complicating chronic bronchitis and emphysema. Lancet. 1981;1(8222):681-686.

2. Continuous or nocturnal oxygen therapy in hypoxemic chronic obstructive lung disease: a clinical trial. Nocturnal Oxygen Therapy Trial Group. Ann Intern Med. 1980;93(3):391-398.

3. Ringbaek TJ, Lange P. Trends in long-term oxygen therapy for COPD in Denmark from 2001 to 2010. Respir Med. 2014;108(3):511-516.

4. Nishi SPE, Zhang W, Kuo Y-F, Sharma G. Oxygen therapy use in older adults with chronic obstructive pulmonary disease. PLoS One. 2015; 10(3):e0120684.

5. Katsenos S, Constantopoulos SH. Long-term oxygen therapy in COPD: factors affecting and ways of improving patient compliance. Pulm Med. 2011;2011:325362.

6. Marti S, Muñoz X, Rios J, Morell F, Ferrer JJ. Body weight and comorbidity predict mortality in COPD patients treated with oxygen therapy. Eur Respir J. 2006;27(4):689-696.

7. Dallari R, Barozzi G, Pinelli G, et al. Predictors of survival in subjects with chronic obstructive pulmonary disease treated with long-term oxygen therapy. Respiration. 2009;61(1):8-13.

8. Haidl P, Clement C, Wiese C, Dellweg D, Köhler D. Long-term oxygen therapy stops the natural decline of endurance in COPD patients with reversible hypercapnia. Respiration. 2004;71(4):342-347.

9. Wedzicha JA, Seemungal TAR. COPD exacerbations: defining their cause and prevention. Lancet. 2007;370(9589):786-796.

10. García-Rivero JL, Esquinas C, Barrecheguren M, et al. Risk factors of poor outcomes after admission for a COPD exacerbation: multivariate logistic predictive models. COPD. 2017;14(2):164-169. 
11. Kim DK, Jacobson FL, Washko GR, et al. Clinical and radiographic correlates of hypoxemia and oxygen therapy in the COPDGene study. Respir Med. 2011;105(8):1211-1221.

12. Budweiser S, Hitzl AP, Jörres RA, Schmidbauer K, Heinemann F, Pfeifer M. Health-related quality of life and long-term prognosis in chronic hypercapnic respiratory failure: a prospective survival analysis. Respir Res. 2007;8:92.

13. Spruit M, Watkins ML, Edwards LD, et al. Determinants of poor 6-min walking distance in patients with COPD: the ECLIPSE cohort. Respir Med. 2010;104(6):849-857.

14. Roca O, Hernández G, Díaz-Lobato S, et al; Spanish Multidisciplinary Group of High Flow Supportive Therapy in Adults (HiSpaFlow). Current evidence for the effectiveness of heated and humidified high flow nasal cannula supportive therapy in adult patients with respiratory failure. Crit Care. 2016;20(1):109.

15. Nishimura M. High-flow nasal cannula oxygen therapy in adults: physiological benefits, indication, clinical benefits, and adverse effects. Respir Care. 2016;61(4):529-541.

16. Hasani A, Chapman TH, McCool D, Smith RE, Dilworth JP, Agnew JE. Domiciliary humidification improves lung mucociliary clearance in patients with bronchiectasis. Chron Respir Dis. 2008;5(2):81-86.

17. Nishimura M. High-flow nasal cannula oxygen therapy in adults. J Intensive Care. 2015;3(1):15.

18. Hernández G, Vaquero C, González P, et al. Effect of postextubation high-flow nasal cannula vs conventional oxygen therapy on reintubation in low-risk patients. JAMA. 2016;315(13):1354.

19. Rea H, McAuley S, Jayaram L, et al. The clinical utility of long-term humidification therapy in chronic airway disease. Respir Med. 2010; 104(4):525-533.

20. Nilius G, Franke KJ, Domanski U, Rühle KH, Kirkness JP, Schneider H. Effects of nasal insufflation on arterial gas exchange and breathing pattern in patients with chronic obstructive pulmonary disease and hypercapnic respiratory failure. Adv Exp Med Biol. 2013;755:27-34.

21. Fraser JF, Spooner AJ, Dunster KR, Anstey CM, Corley A. Nasal high flow oxygen therapy in patients with COPD reduces respiratory rate and tissue carbon dioxide while increasing tidal and end-expiratory lung volumes: a randomised crossover trial. Thorax. 2016;71(8):759-761.

22. Chatila W, Nugent T, Vance G, Gaughan J, Criner GJ. The effects of high-flow vs low-flow oxygen on exercise in advanced obstructive airways disease. Chest. 2004;126(4):1108-1115.

23. Hardinge M, Annandale J, Bourne S, et al; British Thoracic Society Home Oxygen Guideline Development Group, British Thoracic Society Standards of Care Committee. British Thoracic Society guidelines for home oxygen use in adults. Thorax. 2015;70(suppl 1):i1-i43.

24. Global Initiative for Chronic Obstructive Lung Disease (GOLD). Global Strategy for the Diagnosis, Management and Prevention of COPD. Global Initiative for Chronic Obstructive Lung Disease (GOLD); 2013. Available from: http://www.goldcopd.org/. Accessed March 7, 2018.

25. Global Initiative for Chronic Obstructive Lung Disease (GOLD). Global Strategy for the Diagnosis, Management and Prevention of COPD. Global Initiative for Chronic Obstructive Lung Disease (GOLD); 2017. Available from: http://www.goldcopd.org/. Accessed March 7, 2018.

26. Celli BR, MacNee W; ATS/ERS Task Force. Standards for the diagnosis and treatment of patients with COPD: a summary of the ATS/ERS position paper. Eur Respir J. 2004;23(6):932-946.

27. Dhingra N. WHO Guidelines on Drawing Blood: Best Practices in Phlebotomy. WHO publisher: Geneva, Schwitzerland; 2010.

28. Enright PL. The six-minute walk test. Respir Care. 2003;48(8): 783-785.
29. Hurst JR, Vestbo J, Anzueto A, et al; Evaluation of COPD Longitudinally to Identify Predictive Surrogate Endpoints (ECLIPSE) Investigators. Susceptibility to exacerbation in chronic obstructive pulmonary disease. N Engl J Med. 2010;363(12):1128-1138.

30. Husebø GR, Bakke PS, Aanerud M, et al. Predictors of exacerbations in chronic obstructive pulmonary disease - results from the Bergen COPD Cohort Study. PLoS One. 2014;9(10):e109721.

31. Donaldson GC, Wedzicha J. COPD exacerbations 1: epidemiology. Thorax. 2006;61:722-728.

32. Habraken JM, van der Wal WM, Ter Riet G, Weersink EJ, Toben F, Bindels PJ. Health-related quality of life and functional status in endstage COPD: a longitudinal study. Eur Respir J. 2011;37(2):280-288.

33. Agusti AG, Noguera A, Sauleda J, et al. Systemic effects of chronic obstructive pulmonary disease. Eur Respir J. 2003;21:347-360.

34. McCarthy B, Casey D, Devane D, et al. Pulmonary rehabilitation for chronic obstructive pulmonary disease. Cochrane Database Syst Rev. E pub 2015 Feb 23.

35. Dekker-van Weering MGH, Vollenbroek-Hutten MMR, Hermens HJ. Adherence to an online exercise program for COPD patients in the home environment- a pilot study. Health Technol. 2016;6:259-268.

36. Ekström M, Ahmadi Z, Bornefalk-Hermansson A, Abernethy A, Currow D. Oxygen for breathlessness in patients with chronic obstructive pulmonary disease who do not qualify for home oxygen therapy. Cochrane Database Syst Rev. 2016;11:CD006429.

37. Celli BR, Cote CG, Marin JM, et al. The body-mass index, airflow obstruction, dyspnea, and exercise capacity index in chronic obstructive pulmonary disease. $N$ Engl J Med. 2004;350(10):1005-1012.

38. Nagata K, Kikuchi T, Horie T, et al. Domiciliary high-flow nasal cannula oxygen therapy for stable hypercapnic COPD patients: a multicenter, randomized crossover trial. Ann Am Thorac Soc. Epub 2017 Dec 28

39. Struik FM, Lacasse Y, Goldstein RS, Kerstjens HAM, Wijkstra PJ. Nocturnal noninvasive positive pressure ventilation in stable COPD: a systematic review and individual patient data meta-analysis. Respir Med. 2014;108(2):329-337.

40. Bräunlich J, Beyer D, Mai D, Hammerschmidt S, Seyfarth HJ, Wirtz H. Effects of nasal high flow on ventilation in volunteers, COPD and idiopathic pulmonary fibrosis patients. Respiration. 2013;85(4):319-325.

41. Mundel T, Feng S, Tatkov S, Schneider H. Mechanisms of nasal high flow on ventilation during wakefulness and sleep. J Appl Physiol. 2013; 114(8):1058-1065.

42. Möller W, Celik G, Feng S, et al. Nasal high flow clears anatomical dead space in upper airway models. J Appl Physiol. 2015;118(12): 1525-1532.

43. Bhowmik A, Chahal K, Austin G, Chakravorty I. Improving mucociliary clearance in chronic obstructive pulmonary disease. Respir Med. 2009;103(4):496-502.

44. Sundhedsstyrelsen. Chronic Disease Management - A National Strategy. Sundhedsstyrelsen: Copenhagen, Denamrk; 2007.

45. Struik FM, Sprooten RT, Kerstjens HA, et al. Nocturnal non-invasive ventilation in COPD patients with prolonged hypercapnia after ventilatory support for acute respiratory failure: a randomised, controlled, parallel-group study. Thorax. 2014;69(9):826-834.

46. Murphy PB, Rehal S, Arbane G, et al. Effect of home noninvasive ventilation with oxygen therapy vs oxygen therapy alone on hospital readmission or death after an acute COPD exacerbation. JAMA. 2017;317(21):2177.

47. Soler-Cataluña JJ, Martínez-García MA, Román Sánchez P, Salcedo E, Navarro M, Ochando R. Severe acute exacerbations and mortality in patients with chronic obstructive pulmonary disease. Thorax. 2005; 60(11):925-931. 
International Journal of COPD

\section{Publish your work in this journal}

The International Journal of COPD is an international, peer-reviewed journal of therapeutics and pharmacology focusing on concise rapid reporting of clinical studies and reviews in COPD. Special focus is given to the pathophysiological processes underlying the disease, intervention programs, patient focused education, and self management protocols.

This journal is indexed on PubMed Central, MedLine and CAS. The manuscript management system is completely online and includes a very quick and fair peer-review system, which is all easy to use. Visit http://www.dovepress.com/testimonials.php to read real quotes from published authors 